\title{
Gas Hydrate Formation Process for Capture of Carbon Dioxide from Fuel Gas Mixture
}

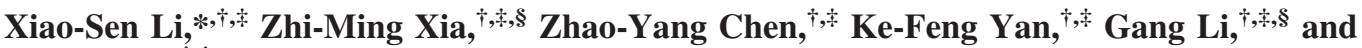 \\ Hui-Jie Wu $\mathbf{u}^{\dagger, *}$
}

Key Laboratory of Renewable Energy and Gas Hydrate, Guangzhou Institute of Energy Conversion, Chinese Academy of Sciences, Guangzhou 510640, People's Republic of China, Guangzhou Center for Gas Hydrate Research, Chinese Academy of Sciences, Guangzhou 510640, People's Republic of China, and Graduate University of Chinese Academy of Sciences, Beijing 100083, People's Republic of China

To determine the suitable operating conditions for the hydrate-based $\mathrm{CO}_{2}$ separation process from a fuel gas mixture, the hydrate nucleation and growth kinetics of the simulated fuel gas (39.2 $\mathrm{mol} \% \mathrm{CO}_{2} / \mathrm{H}_{2}$ gas mixture) in the presence of tetra- $n$-butyl ammonium bromide (TBAB) are investigated. The experiments were conducted at the TBAB concentration range of $0.14-1.00 \mathrm{~mol} \%$, the temperature range of $275.15-282.45 \mathrm{~K}$, the driving force range of $1.00-4.50 \mathrm{MPa}$, the gas/liquid phase ratio range of $0.86-6.47$, and the hydrate growth time of $15-120 \mathrm{~min}$. It is found that the addition of TBAB not only shortens the induction time and accelerates the hydrate growth rate, but also enhances $\mathrm{CO}_{2}$ encaged into the hydrate. However, the number of total moles of gas consumed and the number of moles of $\mathrm{CO}_{2}$ transferred into the hydrate slurry phase decrease with the increase of the TBAB concentration when the TBAB concentration is above $0.29 \mathrm{~mol} \%$. The induction time reduces, and the number of moles of gas consumed, the hydrate formation rate, and the number of moles of $\mathrm{CO}_{2}$ encaged into hydrate phase increase with the increase of the driving force. However, when the driving force is more than $2.5 \mathrm{MPa}, \mathrm{H}_{2}$ prefers to go into the hydrate phase with the increase of the driving force, as compared to $\mathrm{CO}_{2}$. In addition, the temperature has little effect on the hydrate formation process.

\section{Introduction}

It is acknowledged that the emission of carbon dioxide from the burning of fossil fuels is the major contributor to the greenhouse gas emission and subsequent global warming and climate change. Particularly, fossil fuel electric power plants are producing about one-third of $\mathrm{CO}_{2}$ emission worldwide. ${ }^{1} \mathrm{~A}$ promising approach to provide the near future electricity from fossil fuels for the worldwide increasing energy requirements with near-zero $\mathrm{CO}_{2}$ emissions is integrated gasification combined cycle (IGCC) technology with precombustion $\mathrm{CO}_{2}$ capture. ${ }^{2} \mathrm{An}$ essential element of this approach, in fact, is $\mathrm{CO}_{2}$ separation from the mixture of $\mathrm{CO}_{2}$ and $\mathrm{H}_{2}$. Removal of $\mathrm{CO}_{2}$ from the gas mixture can be achieved by a number of separation techniques including absorption into a liquid solvent, adsorption onto a solid, cryogenic separation, and permeation through membranes. However, these methods have the individual issues of either high corrosion, large energy consumption, high cost, or low capacity, and so forth. ${ }^{3}$ Hence, it is urgent to develop an efficient and cost-effective capture/separation technology for the $\mathrm{CO}_{2}$ separation.

A novel method for separating $\mathrm{CO}_{2}$ is via gas hydrate crystallization. ${ }^{4-7}$ The basis for the separation is the selective partition of the $\mathrm{CO}_{2}$ component between the hydrate phase and the gaseous phase. Spencer et al. ${ }^{8}$ gave an economic assessment that the cost of the hydrate technique for $\mathrm{CO}_{2}$ separation from IGCC power plant is approximately 10 U.S. dollars per ton of $\mathrm{CO}_{2}$, which is much lower than that of other methods. Hence,

* To whom correspondence should be addressed. Tel.: +86 20 87057037. Fax: +86 20 87057037. E-mail: lixs@ms.giec.ac.cn.

Guangzhou Institute of Energy Conversion, Chinese Academy of Sciences.

$¥$ Guangzhou Center for Gas Hydrate Research, Chinese Academy of Sciences.

${ }^{\S}$ Graduate University of Chinese Academy of Sciences. the hydrate separation technique is promising for separating $\mathrm{CO}_{2}$ from IGCC fuel gas in the power plants.

Linga et al. ${ }^{4}$ studied the hydrate kinetics of the $\mathrm{CO}_{2} / \mathrm{H}_{2}$ mixture in pure water system. They found that the induction time is $9.7 \mathrm{~min}$ and the hydrate formation rate is $0.0048 \mathrm{~mol} /$ min for the first $5 \mathrm{~min}$ for the $\mathrm{CO}_{2} / \mathrm{H}_{2} / \mathrm{H}_{2} \mathrm{O}$ system at $273.7 \mathrm{~K}$ and 7.5 $\mathrm{MPa}$. Especially, the operating pressure of 7.5 MPa was higher than the outlet pressure of the fuel gas. Hence, there is a continuous interest in using the additives to shorten the induction time, accelerate the hydrate formation rate, and reduce the operating pressure. Some promising additives for the fuel gas mixture are propane $\left(\mathrm{C}_{3} \mathrm{H}_{8}\right)$, cyclopentane $(\mathrm{CP})$, tetrahydrofuran (THF), etc. Zhang et al. ${ }^{5}$ proposed the hydrate-based $\mathrm{CO}_{2}$ capturing process from the precombustion stream with $\mathrm{CP}$. They found that the processes of the two stages of the hydrate formation and dissociation can significantly enrich $\mathrm{CO}_{2}$ from 40 to $98 \mathrm{~mol} \%$ at $282 \mathrm{~K}$. Lee et al. ${ }^{6}$ found that THF of 1.0 $\mathrm{mol} \%$ is the optimum concentration for the $\mathrm{CO}_{2}$ capture based on the kinetic experiments. On the basis of kinetic experiments coupled with the compositional analysis, Kumar et al. ${ }^{7}$ proposed a two-stage hydrate/membrane process with an addition of 2.5 mol $\% \mathrm{C}_{3} \mathrm{H}_{8}$ into the fuel gas mixture. Recently, tetra- $n$-butyl ammonium bromide (TBAB) has taken a particular attraction as an environmentally friendly additive for the gas separation due to small gas molecules $\left(\mathrm{CH}_{4}, \mathrm{CO}_{2}\right)$ that can be engaged into the dodecahedral cavities (S-cage, $5^{12}$ ) of the TBAB hydrate at favorable stability conditions. ${ }^{9}$ Duc et al. ${ }^{10}$ presented the thermodynamic data showing that the addition of $0.29 \mathrm{~mol} \%$ $\mathrm{TBAB}$ can substantially decrease the formation pressure of the $\mathrm{CO}_{2} / \mathrm{N}_{2}$ hydrate. Moreover, the $\mathrm{CO}_{2}$ selectivity in the hydrate phase is at least 4 times better than that in the gas phase. Fan et al. ${ }^{11}$ presented the kinetic data showing that the addition of $0.293 \mathrm{~mol} \% \mathrm{TBAB}$ can shorten the induction time and increase the hydrate formation rate for the $\mathrm{CO}_{2} / \mathrm{N}_{2}$ mixture. However, 


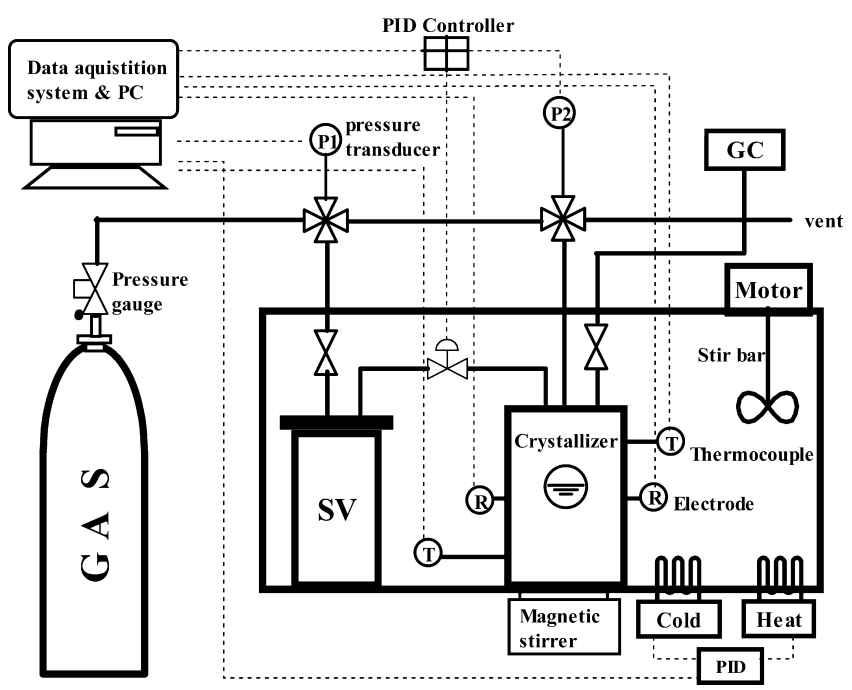

Figure 1. Experimental apparatus.

few studies on the kinetic behavior of the hydrate formation for the $\mathrm{CO}_{2} / \mathrm{H}_{2}$ gas mixture in the presence of TBAB are reported.

The objective of the present work is to investigate into the effects of the TBAB concentration, the gas/liquid phase volume ratio, the driving force, and the experimental temperature on the separation of $\mathrm{CO}_{2}$ from the $\mathrm{CO}_{2} / \mathrm{H}_{2}$ gas mixture based on the kinetic experiments coupled with the compositional analysis and the resistance detecting method.

\section{Experimental Section}

2.1. Materials. A treated synthesis gas coming out of an IGCC power station consists of approximately $40 \mathrm{~mol} \% \mathrm{CO}_{2} /$ $\mathrm{H}_{2}$ gas mixture at a total pressure of $2.5-5 \mathrm{MPa}{ }^{12}$ Thus, a $\mathrm{CO}_{2} / \mathrm{H}_{2}$ gas mixture containing $39.2 \mathrm{~mol} \% \mathrm{CO}_{2}$ was used in the work to simulate a pretreated fuel gas mixture. Tetra- $n$ butyl ammonium bromide (TBAB) with $99.9 \%$ purity was supplied by Shanghai Sinopharm Chemical Reagent Co., Ltd., China. The deionized water with the resistivity of $18.25 \mathrm{~m} \Omega$ $\mathrm{cm}^{-1}$ used in the work was produced by an ultrapure water system supplied by Nanjing Ultrapure Water Technology Co., Ltd., China.

2.2. Apparatus. The experimental apparatus used in this work is shown in Figure 1. The inner volume and the maximum working pressure of the high-pressure crystallizer (CR) are 336 $\mathrm{cm}^{3}$ and $25 \mathrm{MPa}$, respectively. The crystallizer has two circular viewing windows on the front and the back. Mixing of the crystallizer contents is accomplished using a magnetic stir bar $(450 \mathrm{r} / \mathrm{min})$ that is magnetically coupled to a set of the rotating magnet, which is driven by an electric motor (Shanghai Meiyinpu instrument, Ltd., China). Two Pt1000 thermoprobes (JM6081) with $\pm 0.1 \mathrm{~K}$ accuracy are used to measure the temperatures in the gas phase and in the hydrate slurry phase in the crystallizer, respectively. All pressure measurements are determined with Setra smart pressure transducers (model 552, Boxborough, MA, U.S.) with the pressure range of $0-25 \mathrm{MPa}$ and the accuracy of $\pm 0.02 \mathrm{MPa}$. To measure the composition of the gas phase and the hydrate slurry phase in the crystallizer, a Wufeng GC522 gas chromatographer (GC) (Shanghai Wufeng Scientific Instrument CO., Ltd., China.) is connected online with the crystallizer and automated with a personal computer (PC). The crystallizer (CR) and the supply vessel (SV) are immersed in a temperature-controlled bath containing a 30/70 wt \% ethylene glycol/water mixture.
2.3. Procedure. The procedure followed in this work is described in detail elsewhere. ${ }^{13}$ Prior to the experiment, the crystallizer is cleaned using the deionized water and allowed to dry. Next, the TBAB aqueous solution prepared at a desired concentration was injected into the high-pressure hydrate crystallizer to a desired volume. Subsequently, the hydrate crystallizer with the solution was flushed with the $\mathrm{CO}_{2} / \mathrm{H}_{2}$ mixture gas at least four times to remove any residual air, and then it was filled with the $\mathrm{CO}_{2} / \mathrm{H}_{2}$ mixture gas until the desired pressure is reached. Once the temperature was stabilized (typically within $1 \mathrm{~min}$ ) the stirrer in the crystallizer was started, and the experimental time also began to be recorded. During the experiment, the temperature, the pressure, and the resistance in the system were recorded once every $6 \mathrm{~s}$, and the residual gas was sampled and its composition was analyzed with GC at the 5th, 15th, 35th, 60th, and 90th minute. As the gas in the crystallizer was consumed on account of the hydrate formation, additional gas was supplied, and the pressure in the crystallizer was maintained constant with a proportional integral derivative (PID) controller.

The equilibrium hydrate formation conditions for the $\mathrm{CO}_{2}$ / $\mathrm{H}_{2} / \mathrm{TBAB} / \mathrm{H}_{2} \mathrm{O}$ mixtures are required for the kinetic experiments and have been determined in our previous work. ${ }^{14}$ Each gas uptake experiment was carried out at the individual driving force $\left(P_{\text {exp }}-P_{\text {eq }}\right)$, which is the difference of the experimental pressure $\left(P_{\text {exp }}\right)$ from the equilibrium pressure $\left(P_{\text {eq }}\right)$. Table 1 provides the list of the experimental conditions.

2.4. Amount of Gas Consumed. The number of moles of the gas $\left(\Delta n_{\mathrm{H}}\right)$ that has either gone into the water or been consumed from the hydrate formation can be calculated as follows: ${ }^{4}$

$$
\begin{gathered}
\Delta n_{\mathrm{H}}=n_{\mathrm{H}, t}-n_{\mathrm{H}, 0} \\
=\left(\frac{P V}{z R T}\right)_{\mathrm{G}, 0}-\left(\frac{P V}{z R T}\right)_{\mathrm{G}, t}+\left(\frac{P V}{z R T}\right)_{\mathrm{SV}, 0}-\left(\frac{P V}{z R T}\right)_{\mathrm{SV}, t}
\end{gathered}
$$

where $z$ is the compressibility factor calculated by Pitzer's correlation, ${ }^{15}$ subscript $t$ refers to time $t$, subscript 0 refers to the initial time, subscript $G$ refers to the gas phase in the crystallizer, and subscript SV refers to the gas phase in the supply vessel.

During the kinetic experiment, the composition of the gas phase is determined by GC. At any given time by knowing the composition of the gas mixture in the crystallizer, the number of moles of the individual gas component consumed for the hydrate formation can be calculated by the component mass balance.

$$
\begin{gathered}
\Delta n_{\mathrm{H}}^{i}=n_{\mathrm{H}, t}^{i}-n_{\mathrm{H}, 0}^{i} \\
=\left(y^{i} \frac{P V}{z R T}\right)_{\mathrm{G}, 0}-\left(y^{i} \frac{P V}{z R T}\right)_{\mathrm{G}, t}+\left(y^{i} \frac{P V}{z R T}\right)_{\mathrm{SV}, 0}-\left(y^{i} \frac{P V}{z R T}\right)_{\mathrm{SV}, t} \\
=V_{\mathrm{G}}\left[\left(y^{i} \frac{P}{z R T}\right)_{\mathrm{G}, 0}-\left(y^{i} \frac{P}{z R T}\right)_{\mathrm{G}, t}\right]+y_{\mathrm{SV}}^{i} V_{\mathrm{SV}}\left[\left(\frac{P}{z R T}\right)_{\mathrm{SV}, 0}-\left(\frac{P}{z R T}\right)_{\mathrm{SV}, t}\right]
\end{gathered}
$$

where superscript $i$ refers to the component of the gas mixture, and $y$ is the mole fraction. It is assumed that the volume changes due to phase transitions are neglected.

\section{Results and Discussion}

In this work, a total of 18 kinetic experimental runs were carried out at the different conditions including the fresh and memory water (runs 1 and 2), the gas/liquid phase volume ratio (runs 2-5), the experimental temperature (runs 2, 6-8), the TBAB concentration (runs 2, 9-12), and the driving force (runs $2,13-18)$ to find the suitable operating condition for $\mathrm{CO}_{2}$ 
Table 1. Experimental Conditions along with Measured Induction Time and Hydrate Formation Rates for Different Systems

\begin{tabular}{|c|c|c|c|c|c|c|c|c|c|}
\hline items & $\mathrm{F}^{a} / \mathrm{M}^{b}$ & $x,^{c} \mathrm{~mol} \%$ & $R_{\mathrm{v}}{ }^{d}$ & $T,{ }^{e} \mathrm{~K}$ & $\mathrm{DF}_{,}^{f} \mathrm{MPa}$ & time $_{\mathrm{R}}{ }^{g}$ min & time $_{\mathrm{I}},{ }^{h}$ min & $n,{ }^{i} \mathrm{~mol}$ & $R_{\mathrm{f}}{ }^{j} \mathrm{~mol} / \mathrm{min}$ \\
\hline run 1 & F & 0.29 & 0.86 & 278.15 & 2.50 & 90 & 13.4 & $3.82 \times 10^{-2}$ & $7.26 \times 10^{-3}$ \\
\hline run 2 & M & 0.29 & 0.86 & 278.15 & 2.50 & 90 & 5.8 & $2.02 \times 10^{-2}$ & $7.32 \times 10^{-3}$ \\
\hline run 3 & M & 0.29 & 6.47 & 278.15 & 2.50 & 90 & 6.0 & $2.07 \times 10^{-2}$ & $2.79 \times 10^{-3}$ \\
\hline run 5 & M & 0.29 & 1.49 & 278.15 & 2.50 & 90 & 5.9 & $1.98 \times 10^{-2}$ & $7.23 \times 10^{-3}$ \\
\hline run 6 & M & 0.29 & 0.86 & 277.05 & 2.50 & 90 & 5.9 & $1.95 \times 10^{-2}$ & $7.24 \times 10^{-3}$ \\
\hline run 7 & M & 0.29 & 0.86 & 279.55 & 2.50 & 90 & 6.1 & $1.99 \times 10^{-2}$ & $7.28 \times 10^{-3}$ \\
\hline run 10 & M & 0.21 & 0.86 & 276.25 & 2.50 & 90 & 8.5 & $2.19 \times 10^{-2}$ & $5.94 \times 10^{-3}$ \\
\hline run 11 & M & 0.50 & 0.86 & 280.35 & 2.50 & 90 & 4.2 & $1.96 \times 10^{-2}$ & $8.38 \times 10^{-3}$ \\
\hline run 12 & M & 1.00 & 0.86 & 282.45 & 2.50 & 90 & 3.0 & $1.89 \times 10^{-2}$ & $9.36 \times 10^{-3}$ \\
\hline run 13 & M & 0.29 & 0.86 & 278.15 & 1.00 & 90 & 43 & $3.95 \times 10^{-2}$ & $9.25 \times 10^{-4}$ \\
\hline run 14 & M & 0.29 & 0.86 & 278.15 & 1.50 & 90 & 13 & $3.30 \times 10^{-2}$ & $3.95 \times 10^{-3}$ \\
\hline run 15 & M & 0.29 & 0.86 & 278.15 & 2.00 & 90 & 8.5 & $2.19 \times 10^{-2}$ & $4.58 \times 10^{-3}$ \\
\hline run 16 & M & 0.29 & 0.86 & 278.15 & 3.00 & 90 & 4.1 & $2.22 \times 10^{-2}$ & $7.67 \times 10^{-3}$ \\
\hline
\end{tabular}

${ }^{a}$ Fresh water. ${ }^{b}$ Memory water. ${ }^{c}$ TBAB concentration in aqueous solution. ${ }^{d}$ Gas/liquid phase volume ratio. ${ }^{e}$ Experimental temperature. ${ }^{f}$ Driving force $\left(P_{\mathrm{exp}}-P_{\mathrm{eq}}\right) .{ }^{g}$ Reacted time. ${ }^{h}$ Induction time. ${ }^{i}$ Moles of gas consumed at nucleation point (induction time). ${ }^{j}$ Rate of hydrate growth (gas consumption rate for the first 5 min after nucleation).

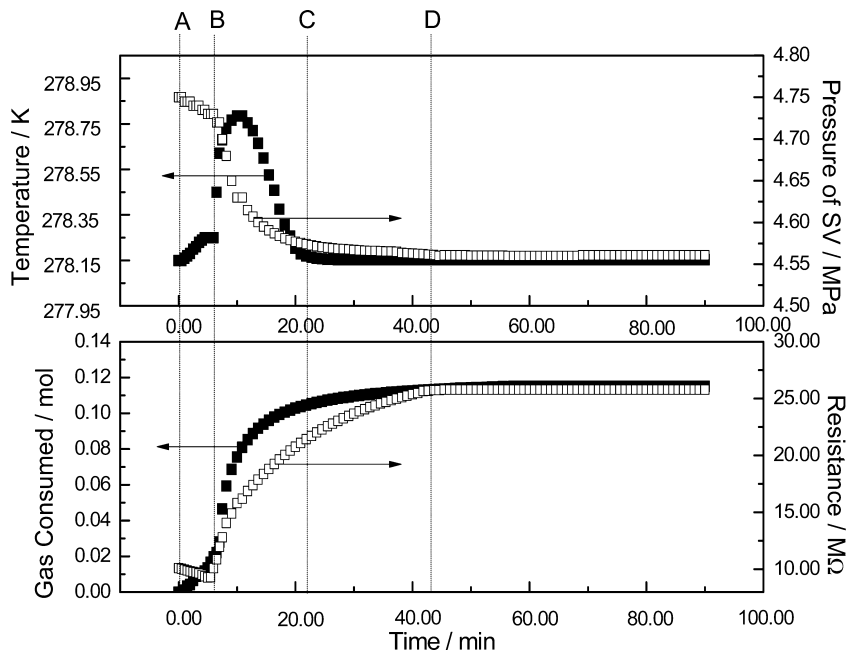

Figure 2. Change curves of pressure of SV, temperature, resistance, and gas uptake for hydrate formation from the system with $0.29 \mathrm{~mol} \% \mathrm{TBAB}$ at $278.15 \mathrm{~K}$ and driving force of $2.50 \mathrm{MPa}$.

separation from IGCC fuel gas via the hydrate formation. Table 1 summarizes the results from the kinetic experiments at the different conditions.

3.1. Hydrate Formation Process and Induction Time. Figure 2 gives the typical change trends of the pressure of the $\mathrm{SV}$, the temperature, and the resistance in the system and the moles of gas consumed during hydrate formation in the presence of $0.29 \mathrm{~mol} \% \mathrm{TBAB}$ at the feed pressure of 3.0 MPa and the bath temperature of $278.15 \mathrm{~K}$, as shown in run 2 . It can be seen from Figure 2 that the hydrate formation process consists of three periods. The period from $A$ to $B$, which takes approximately $5.8 \mathrm{~min}$, is the process of the gas dissolution and the hydrate nucleation. $A$ is the initial time of the experiment, that is, when the system starts to be stirred. $B$ is the beginning time of the hydrate formation. During the period, the temperature slightly increases from 278.15 to $278.25 \mathrm{~K}$ due to the stirring, the pressure of the SV slightly decreases with the slight increase of the moles of gas consumed due to the gas dissolution, and the system resistance slightly reduces on account of the effect of the weak ions, $\mathrm{HCO}_{3}^{-}$and $\mathrm{H}^{+}$, in the solution resulted from the reaction of the dissolved $\mathrm{CO}_{2}$ with $\mathrm{H}_{2} \mathrm{O}$. The period from $B$ to $C$ is the process of extensive hydrate formation, which takes approximately $17 \mathrm{~min}$. In the process, the temperature in the system sharply increases from 278.25 to $278.85 \mathrm{~K}$ within a short time, and then gradually decreases to $278.15 \mathrm{~K}$. This period is a process of the phase transformation of gas and water to solid hydrate, which creates the heat of hydrate formation and results in the increase of the temperature in the system. In this period, the pressure of the SV reduces quickly with the rapid increase of the number of the gas consumption on account of the extensive gas hydrate formation. The phenomena are similar to those observed by Linga et al. and Lee et al. ${ }^{4,6}$ In addition, it is found that the system resistance gradually increases over time in the process. It is due to the fact that the solid hydrate formed by water, dissolved $\mathrm{CO}_{2}$, the ions of $\mathrm{Br}$, and tetra- $n$-butyl ammonium causes the decreases of the concentrations of the ions of $\mathrm{Br}$ and tetra- $n$-butyl ammonium in the TBAB solution. Thus, the decrease of the number of moles of the free ions in the solution and the increase of the amount of the hydrate slurry in the process of the hydrate formation result in the reduction of the electric conductivity in the system, that is, the increase of the system resistance. In the period from $C$ to $D$, the temperature has little change, the system resistance continues increasing gradually, and the pressure continues reducing slowly with the slow increase of the moles of the consumed gas. This is because a small amount of the hydrate continues forming during the period. The process takes approximately $20 \mathrm{~min}$. After point $D$, the temperature, the pressure, the resistance, and the consumption of the gas all have no change with time. This illustrates that the hydrate formation has completed at point $D$. A similar process can also be observed in other runs.

3.2. Effect of Memory Water. Memory refers to the situation where water that is used in the experiment has experienced the hydrate formation. ${ }^{13}$ Table 1 gives the induction time for the hydrate formation from the systems with fresh and memory water in the presence of $0.29 \mathrm{~mol} \% \mathrm{TBAB}$ at $278.15 \mathrm{~K}$ and the driving force of $2.50 \mathrm{MPa}$ for runs 1 and 2 . It can be found that the induction time required in the system with memory water is $5.8 \mathrm{~min}$, and it is obviously shorter than that with fresh water, $13.4 \mathrm{~min}$. This observation agrees with what is described by Bishnoi and Natarajan. ${ }^{16}$ Actually, the operation with memory water is practical and feasible for the industrial continuous loop. Thus, the following experiments were conducted with memory water.

3.3. Effect of Gas/Liquid Phase Volume Ratio. The gas/ liquid phase volume ratio $\left(R_{\mathrm{v}}\right)$ is defined as the ratio of the 


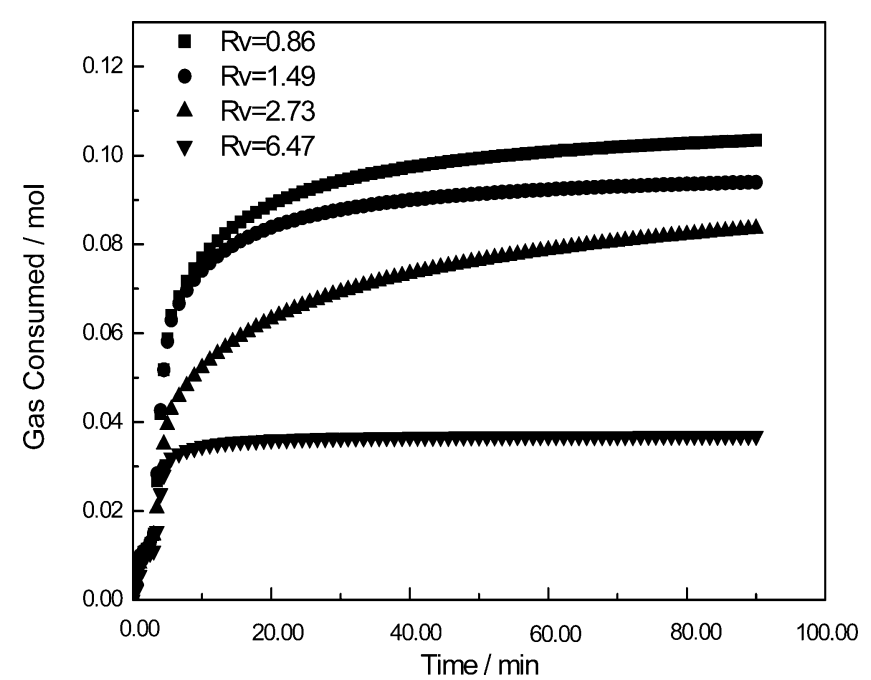

Figure 3. Gas uptake curves for hydrate formation from the system with $0.29 \mathrm{~mol} \%$ TBAB with different gas/liquid phase volume ratios at 278.15 $\mathrm{K}$ and driving force of $2.50 \mathrm{MPa}$.

volume of the gas phase $\left(V_{\mathrm{G}}\right)$ to the volume of the liquid phase $\left(V_{\mathrm{L}}\right)$ in the crystallizer. Figure 3 gives the comparison of the gas uptake curves for the hydrate formation with the gas/liquid phase volume ratio of $0.86-6.47$ in the presence of $0.29 \mathrm{~mol}$ $\% \mathrm{TBAB}$ at $278.15 \mathrm{~K}$ and the driving force of $2.50 \mathrm{MPa}$, as shown in runs 2 to 5 . As seen from the Figure 3, the number of the total moles of the gas consumed during hydrate formation increases as $R_{\mathrm{v}}$ reduces from 6.47 to 0.86 . For example, the number of moles of gas consumed at the end of the hydrate formation is up to $0.1044 \mathrm{~mol}$ at $R_{\mathrm{v}}=0.86$, while it is only $0.0497 \mathrm{~mol}$ at $R_{\mathrm{v}}=6.47$. This interesting phenomenon can be explained as follows: because the inter volume of the crystallizer $\left(V_{\mathrm{C}}\right)$ is constant, $R_{\mathrm{V}}=\left(V_{\mathrm{C}}-V_{\mathrm{L}}\right) / V_{\mathrm{L}}=V_{\mathrm{C}} / V_{\mathrm{L}}-1$ is only a function of the volume of the liquid phase $\left(V_{\mathrm{L}}\right)$ in the crystallizer, and the value of $R_{\mathrm{v}}$ decreases with the increase of the amount of the TBAB solution. That is, in this work, the liquid phase volume increases from 45 to $180 \mathrm{~mL}$ as the gas/liquid phase volume ratio decreases from 6.47 to 0.86 . The bigger liquid phase volume means more moles of TBAB existing in the solution for the hydrate formation. Thus, at the given condition, the more moles of TBAB in the solution results in the more TBAB hydrate formed with more enclosed gas. This is why the moles of gas consumed increase as the $\left(R_{\mathrm{v}}\right)$ decreases. Therefore, in the following experiments, $R_{\mathrm{v}}=0.86$ corresponding to the liquid volume of $180 \mathrm{~mL}$ was chosen to obtain the highest gas consumption resulting in the highest amount of the formed hydrate. In addition, it is found that the gas/liquid phase volume ratio has no effect on the induction time, as shown in Figure 3.

3.4. Effect of Experimental Temperature. Figure 4 shows the gas uptake measurements for hydrate formation from the system with $0.29 \mathrm{~mol} \% \mathrm{TBAB}$ at the driving force of 2.50 $\mathrm{MPa}$ and the different temperatures, as shown in runs $2,6-8$. The results show that the value of the gas uptake and the gas consumption rate at the fixed time and the induction time have no significant change with the change of the temperature. The above phenomenon illustrates that the temperature change has little effect on the kinetic behavior of the hydrate formation with the given driving force.

3.5. Effect of TBAB Concentration. As shown in runs 2, 9-12, for the systems with the TBAB concentration of 0.14-1.00 mol \%, the experiments were carried out at the temperatures whose equilibrium hydrate formation pressure is

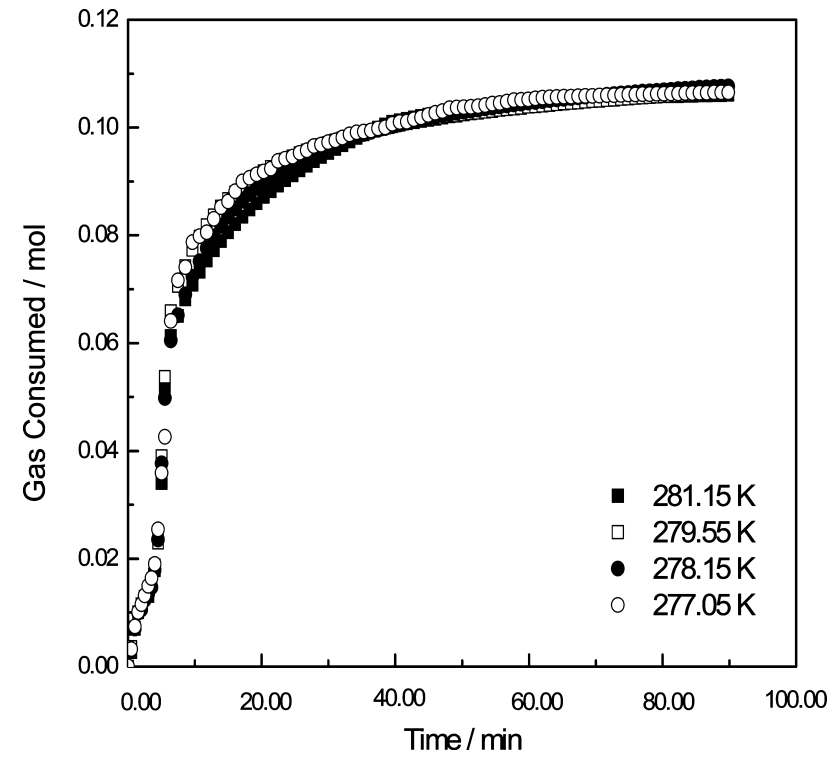

Figure 4. Gas uptake curves for hydrate formation from the system with $0.29 \mathrm{~mol} \% \mathrm{TBAB}$ at different experimental temperatures and driving force of $2.50 \mathrm{MPa}$.

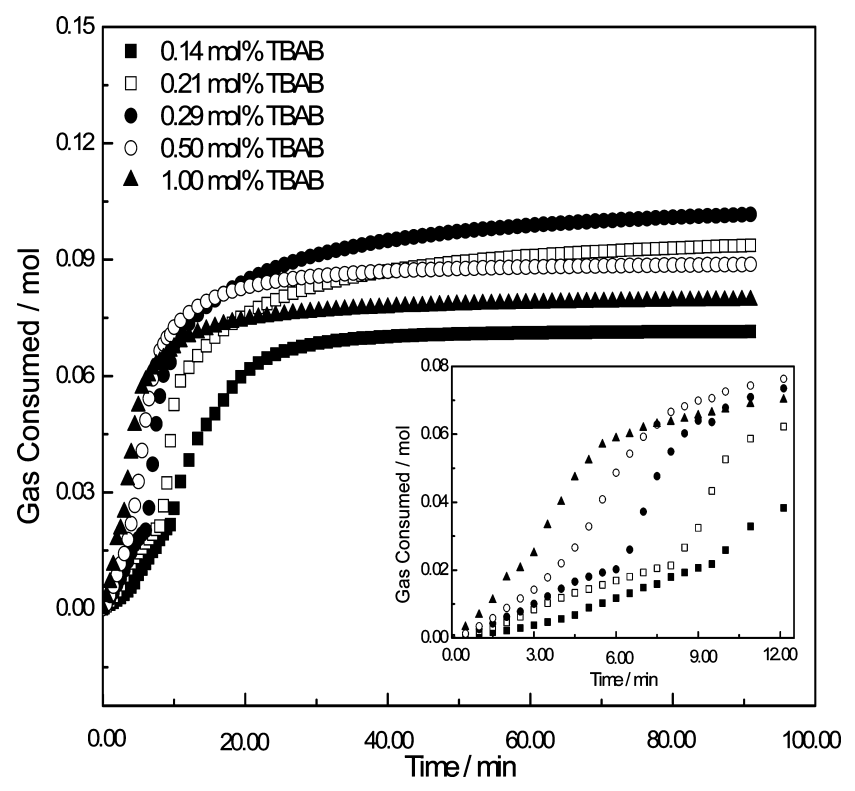

Figure 5. Gas uptake curves for hydrate formation from the systems with different TBAB concentrations at driving force of $2.50 \mathrm{MPa}$.

$0.50 \mathrm{MPa}$ with the above different TBAB concentrations. The data of the equilibrium hydrate formation condition have been measured in our previous work. ${ }^{14}$ Thus, all the experimental pressures are fixed at 3.0 MPa to obtain the driving force of 2.50 MPa. The experimental data are summarized in Table 1 $(2,9-12)$ and plotted in Figure 5. It can be seen from Figure 5 that the hydrate forms quickly with the TBAB concentration from 0.21 to $1.00 \mathrm{~mol} \%$ except for the TBAB concentration of $0.14 \mathrm{~mol} \%$, for which the induction time is $9.5 \mathrm{~min}$, and the induction time reduces with the increase of the TBAB concentration. However, it is not the higher TBAB concentration that causes the more gas consumed. The number of total moles of gas consumed increases with the increase of TBAB concentration in the lower concentration range. However, it decreases with increasing the TBAB concentration when the TBAB concentration is more than $0.29 \mathrm{~mol} \%$. For example, the number of total moles of gas consumed with the TBAB concentrations of $0.14,0.21$, and $0.29 \mathrm{~mol} \%$ is $0.0897,0.0988$, and 0.1047 


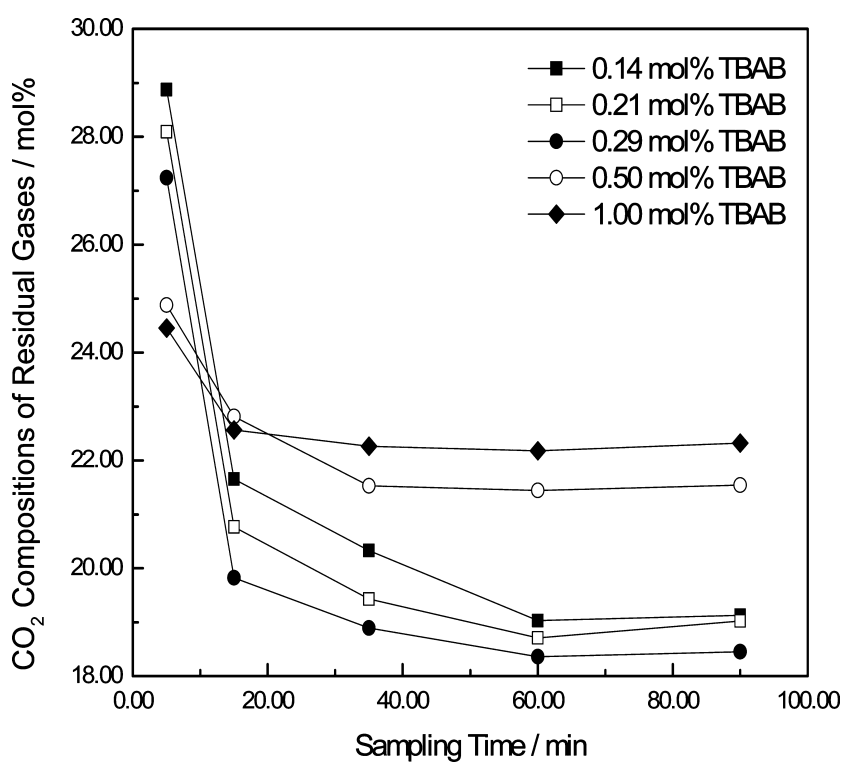

Figure 6. $\mathrm{CO}_{2}$ compositions of residual gases in the systems with different $\mathrm{TBAB}$ concentrations in the process of hydrate formation at driving force of $2.50 \mathrm{MPa}$.

mol, respectively, which exhibits an increase trend, whereas, with the TBAB concentrations of 0.50 and $1.00 \mathrm{~mol} \%$, the number of total moles of the gas consumed is only 0.0949 and 0.0894 mol, respectively, which shows a decrease trend. It may be due to the fact that the gas hydrate sharply forms substantially and agglomerates at the gas/liquid interface when TBAB concentration is relatively high. Extensive hydrate formation and crystal agglomeration results in the accumulation of crystals as stagnant pockets at the gas/water interface, which prevents more gas from coming into contact with the water. A similar phenomenon can be found elsewhere. ${ }^{4}$ The more agglomeration results in the smaller amount of the gas into the solution for the hydrate formation.

The residual gas compositions in the systems with $0.14-1.00$ mol \% $\mathrm{TBAB}$ at driving force of $2.50 \mathrm{MPa}$ are given in Figure 6. As seen in Figure 6, the $\mathrm{CO}_{2}$ composition in the residual gas phase in the system with the given TBAB concentration decreases with time from 0 to $60 \mathrm{~min}$, and then slightly increases with time from 60 to $90 \mathrm{~min}$. For example, the $\mathrm{CO}_{2}$ composition in the residual gas phase in the system with $0.29 \mathrm{~mol} \%$ TBAB substantially decreases from 39.2 to $18.36 \mathrm{~mol} \%$ with time from 0 to $60 \mathrm{~min}$, and then slightly rises to $18.45 \mathrm{~mol} \%$ at the 90th minute. On the other hand, in the systems with the different TBAB concentrations, the $\mathrm{CO}_{2}$ composition in the residual gas during the hydrate growth decreases as the TBAB concentration increases from 0.14 to $0.29 \mathrm{~mol} \%$ at a certain time. However, it is not the higher TBAB concentration that causes the lower $\mathrm{CO}_{2}$ composition in the residual gas. On the contrary, when the TBAB concentration is more than $0.29 \mathrm{~mol} \%$, the $\mathrm{CO}_{2}$ composition in the residual gas is higher than that with 0.29 mol \% TBAB at the given time after $15 \mathrm{~min}$ and increases with the increase of the TBAB concentration. It is because, as mentioned above, the gas hydrate sharply forms substantially and agglomerates at the gas/liquid interface when the TBAB concentration is relatively high. The agglomeration of the hydrate at the gas/liquid interface hinders the further mass transfer of $\mathrm{CO}_{2}$ into the aqueous solution. The more agglomeration results in the smaller amount of $\mathrm{CO}_{2}$ into the solution for the hydrate formation. Relatively, $\mathrm{H}_{2}$ molecule is smaller than $\mathrm{CO}_{2}$ molecule and more easily goes through the layer of the hydrate agglomeration at the gas/liquid interface transferring

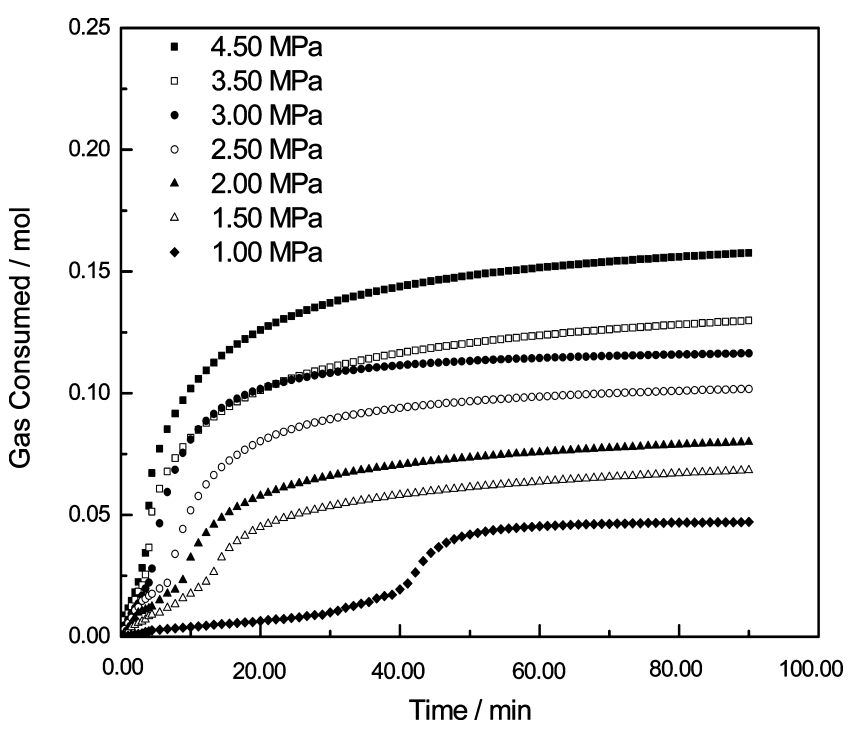

Figure 7. Gas uptake curves for hydrate formation from the system with $0.29 \mathrm{~mol} \% \mathrm{TBAB}$ at $278.15 \mathrm{~K}$ and different driving forces.

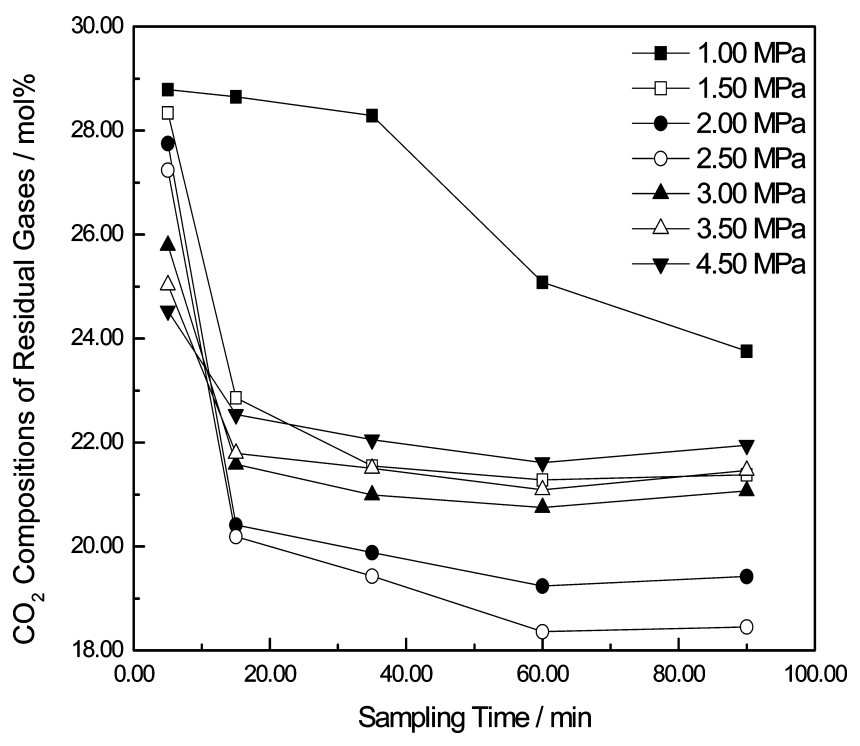

Figure 8. $\mathrm{CO}_{2}$ compositions of residual gases in the system with $0.29 \mathrm{~mol}$ $\% \mathrm{TBAB}$ in the process of hydrate formation at $278.15 \mathrm{~K}$ and different driving forces.

into the aqueous solution. Furthermore, this causes the increase of the $\mathrm{CO}_{2}$ composition of the residual gas phase with the high concentration of TBAB.

3.6. Effect of Driving Force. Figure 7 shows the comparison of the gas uptake curves for the hydrate formation from the system with $0.29 \mathrm{~mol} \% \mathrm{TBAB}$ at $278.15 \mathrm{~K}$ and the driving force of 1.0-4.5 $\mathrm{MPa}$, as shown in runs 2, 13-18. As seen from Figure 7, the induction time decreases with the increase of the driving force. For example, the induction time was 43 min with 1.0 MPa driving force, while it is only $3.0 \mathrm{~min}$ with 4.5 $\mathrm{MPa}$ driving force. In addition, the gas consumption rate and the total moles of gas consumed increase with increasing the driving force. This is attributed to the fact that, on one hand, the higher driving force makes more gas going into the aqueous solution and furthermore causes more gas hydrate formed, resulting in more gas consumed; on the other hand, the increase of the amount of the gas going into the solution correlates with the enhancement of the gas hydrate growth rate, which also means the enhancement of the gas consumption rate. Figure 8 shows the changes of the $\mathrm{CO}_{2}$ compositions in the residual gas 
phase versus time under the same experimental conditions with Figure 7. As seen in Figure 8, the $\mathrm{CO}_{2}$ composition in the residual gas phase decreases substantially with time at the given driving force except for 1.0 MPa. It is for this reason that $\mathrm{CO}_{2}$ in the gas phase is preferentially incorporated into the hydrate phase in the process of the hydrate formation to reach the thermodynamic equilibrium due to that the equilibrium hydrate formation pressure of $\mathrm{CO}_{2}$ is much lower than that of $\mathrm{H}_{2}$. Furthermore, the process makes the $\mathrm{CO}_{2}$ content in the residual gas phase reduce with time. However, it does not mean that the higher driving force causes the lower $\mathrm{CO}_{2}$ composition in the residual gas phase. For example, the $\mathrm{CO}_{2}$ composition in the residual gas phase decreases as the driving force increases from 1.0 to $2.5 \mathrm{MPa}$ at the certain time. On the contrary, the $\mathrm{CO}_{2}$ content in the residual gas phase increases as the driving force increases from 3.0 to 4.5 $\mathrm{MPa}$, which can be attributed to the fact that $\mathrm{H}_{2}$ competes with $\mathrm{CO}_{2}$ for hydrate cage $\left(5^{12}\right)$ occupancy at the higher driving force. The observed phenomenon is in agreement with the report by Linga et al. ${ }^{4}$

\section{Conclusions}

The hydrate nucleation and growth kinetics of the $\mathrm{CO}_{2} / \mathrm{H}_{2} /$ TBAB hydrate systems are investigated at the different conditions. The total moles of gas consumed increase with the gas/ liquid phase volume ratio, which has no effect on the induction time. The driving force can shorten the induction time and promote the hydrate formation. The induction time reduces, and the total moles of the consumed gas corresponding to the amount of the hydrate formation, the hydrate formation rate, and the amount of $\mathrm{CO}_{2}$ encaged into hydrate phase increase with the increase of the driving force. However, when the driving force is more than $2.50 \mathrm{MPa}, \mathrm{H}_{2}$ prefers to going to the hydrate phase with the increase of the driving force, as compared to $\mathrm{CO}_{2}$. The temperature has little effect on the hydrate formation process. The presence of TBAB not only shortens the reduction time and accelerates the hydrate formation rate, but also enhances $\mathrm{CO}_{2}$ going into hydrate phase. With the increase of the TBAB concentration, the induction time of the hydrate formation reduces, and the moles of the consumed gas, the hydrate formation rate, and the amount of $\mathrm{CO}_{2}$ encaged into hydrate phase increase. However, when the TBAB concentration is more than $0.29 \mathrm{~mol} \%$, the moles of the consumed gas and the moles of $\mathrm{CO}_{2}$ transferring into the hydrate phase decrease with the increase of the TBAB concentration. The above results provide the kinetic data and the support for the development of the process for the $\mathrm{CO}_{2}$ recovery from IGCC fuel gas.

\section{Acknowledgment}

This work was supported by the National Natural Science Foundation of China (20773133, 51076155), the Science \&
Technology Program of Guangdong Province (2009B050600006), and the CAS Knowledge Innovation Program (KGCX2-YW3X6), which are gratefully acknowledged.

\section{Literature Cited}

(1) Kusuda, S. The international symposium on ocean disposal of carbon dioxide. Waste Manage. 1998, 17, 279-280.

(2) Barchas, R.; Davis, R. The Kerr-Mcgee abb lummus crest technology for the recovery of $\mathrm{CO}_{2}$ from stack gases. Energy Convers. Manage. 1992, $33,333-340$

(3) Aaron, D.; Tsouris, C. Separation of $\mathrm{CO}_{2}$ from flue gas: a review. Sep. Sci. Technol. 2005, 40, 321-348.

(4) Linga, P.; Kumar, R.; Englezos, P. Gas hydrate formation from hydrogen/carbon dioxide and nitrogen/carbon dioxide gas mixtures. Chem. Eng. Sci. 2007, 62, 4268-4276.

(5) Zhang, J. S.; Yedlapalli, P.; Lee, J. W. Thermodynamic analysis of hydrate-based pre-combustion capture of $\mathrm{CO}_{2}$. Chem. Eng. Sci. 2009, 64, $4732-4736$.

(6) Lee, H. J.; Lee, J. D.; Linga, P.; Englezos, P.; Kim, Y. S.; Lee, M. S.; Kim, Y. D. Gas hydrate formation process for pre-combustion capture of carbon dioxide. Energy 2010, 35, 2729-2733.

(7) Kumar, R.; Linga, P.; Ripmeester, J. A.; Englezos, P. Two-stage clathrate hydrate/membrane process for precombustion capture of dioxide and hydrogen. J. Environ. Eng. 2009, 135, 411-417.

(8) Spencer, D. F.; Tam, S. S.; Deppe, G.; Currier, R. F.; Young, J. S.; Anderson, G. K. Carbon Dioxide Separation from a High Pressure Shifted Synthesis Gas; Proceedings of 19th Annual International Pittsburgh Coal Conference: Pittsburgh, PA, 2002.

(9) Arjmandi, M.; Chapoy, A.; Tohidi, B. Equilibrium data of hydrogen, methane, nitrogen, carbon dioxide, and natural gas in semi-clathrate hydrates of tetrabutyl ammonium bromide. J. Chem. Eng. Data 2007, 52, $2153-$ 2158 .

(10) Duc, N. H.; Chauvy, F.; Herri, J. M. $\mathrm{CO}_{2}$ capture by hydrate crystallization - A potential solution for gas emission of steelmaking industry. Energy Convers. Manage. 2007, 48, 1313-1322.

(11) Fan, S. S.; Li, S. F.; Wang, J. Q.; Lang, X. M.; Wang, Y. H. Efficient capture of $\mathrm{CO}_{2}$ from simulated flue gas by formation of TBAB or TBAF semiclathrate hydrates. Energy Fuels 2009, 23, 4202-4208.

(12) Klara, S. M.; Srivastava, R. D. US DOE integrated collaborative technology development program for $\mathrm{CO}_{2}$ separation and capture. Environ. Prog. 2002, 21, 247-253.

(13) Lee, J. D.; Susilo, R.; Englezos, P. Kinetics of structure H gas hydrate. Energy Fuels 2005, 19, 1008-1015.

(14) Li, X. S.; Xia, Z. M.; Chen, Z. Y.; Yan, K. F.; Li, G.; Wu, H. J. Equilibrium hydrate formation conditions for the mixtures of $\mathrm{CO}_{2}+\mathrm{H}_{2}+$ tetrabutyl ammonium bromide. J. Chem. Eng. Data 2010, 55, 2180-2184.

(15) Smith, J. M.; Van Ness, H. C.; Abbott, M. M. Introduction to Chemical Engineering Thermodynamics; McGraw-Hill: New York, 2001.

(16) Bishnoi, P. R.; Natarajan, V. Formation and decomposition of gas hydrates. Fluid Phase Equilib. 1996, 117, 168-177.

Received for review April 10, 2010 Revised manuscript received September 1, 2010 Accepted October 1, 2010

IE100851U 